\title{
CONCEPTUAL DESIGN OF BIRD-LIKE UNMANNED AERIAL VEHICLE FOR PEST BIRD CONTROL Buyung Junaidin ${ }^{1}$, Dwi Hartini ${ }^{2}$, Santo Herlambang ${ }^{3}$ \\ ${ }^{1,2}$ Departemen Teknik Dirgantara, Sekolah Tinggi Teknologi Adisutjipto Jl. Janti Blok-R Lanud Adisutjipto Yogyakarta \\ buyung112011@gmail.com
}

\begin{abstract}
Finch (Lonchura) pest bird becomes a serious problem for rice-plant farmers when entering harvest period because it could make crop yields decreases or even crop failure. There are many method have been done for pest bird control but almost all of those are not effectives. Bird-like unmanned aerial vehicle is proposed as an alternative solution to control pest bird. The aim of this research is to do conceptual design of unmanned aerial vehicle which look like predator bird for pest bird control in farm area. The predator bird which means is black eagle (Ictinaetus Malaiensis) which is one of natural predators of small birds including finch family. Conceptual design of bird-like unmanned aerial vehicle follows general design process of aircraft with some simplification. Method of design adopt to Raymer's method and sketching of black eagle planform especially wings and tail. The design results an unmanned aerial vehicle look like black eagle with cruise speed $\left(v_{c}\right)$ is $10 \mathrm{~m} / \mathrm{s}$ and operational altitude $120 \mathrm{~m}$ above sea level. From aerodynamics analysis shows that bird-like unmanned aerial vehicle which have designed fill lift requirement at angle of attack $(\alpha) 3^{o}$ and longitudinal static stability criteria.
\end{abstract}

Keyword: Conceptual Design, Unmanned Aerial Vehicle, Bird-like.

Abstrak

Hama burung pipit (Lonchura) menjadi salah satu masalah serius bagi petani padi ketika memasuki masa panen karena dapat menyebabkan berkurangnya hasil panen atau bahkan gagal panen. Banyak cara yang telah dilakukan petani dalam mengusir hama burung namun hampir semuanya kurang atau bahkan efektif. Pesawat udara tanpa awak mirip burung diharapkan bisa menjadi salah satu solusi yang tepat untuk mengatasi hama burung. Tujuan dari penelitian ini adalah melakukan proses perancangan awal pesawat udara tanpa awak mirip burung predator untuk tujuan pengendalian hama burung di lahan pertanian. Burung predator yang ditiru adalah burung elang hitam (Ictinaetus Malaiensis) yang merupakan salah satu predator alami burung - burung kecil termasuk burung pipit. Perancangan awal pesawat udara tanpa awak mirip burung mengikuti proses perancangan pesawat pada umumnya dengan beberapa penyederhanaan. Metode perancangan mengacu pada metode Raymer dan meniru planform sayap dan ekor burung elang melalui proses sketching. Hasil perancangan diperoleh geometri pesawat yang menyerupai burung elang hitam dengan kecepatan terbang jelajah $\left(v_{c}\right)$ $10 \mathrm{~m} / \mathrm{s}$ dan ketinggian terbang $120 \mathrm{~m}$ di atas permukaan laut. Hasil simulasi aerodinamika menunjukkan bahwa rancangan pesawat memenuhi syarat kebutuhan gaya angkat untuk pesawat pada sudut serang $(\alpha) 3^{\circ}$ dan memenuhi kriteria kestabilan statis longitudinal.

Kata Kunci: Perancangan awal, Pesawat Udara Tanpa Awak, Mirip Burung

\section{Pengantar}

Saat ini banyak petani padi yang mengeluh akibat hasil panen yang berkurang, salah satu penyebabnya adalah serangan hama burung yang secara berkelompok. Spesies burung yang paling sering menimbulkan kerugian serius adalah burung pipit (Lonchura). Orang- 
orangan sawah yang dibuat petani sudah tidak efektif, bahkan orang-orangan sawah sering kali dihinggapi oleh kawanan hama burung. Selain itu, metode menghalau hama burung dengan menyebar plastik mengkilap serta kepingan CD di sekitar sawah bukan solusi tepat, karena puncak serangan hama burung adalah pagi hari antara pukul 06.00 sampai pukul 10.00 dan sore hari antara pukul 14.00 sampai dengan pukul 16.00. Oleh karena itu, dari berbagai macam cara yang telah dilakukan para petani untuk menghalau hama burung ini dinilai kurang efektif.

Pesawat udara tanpa awak mirip burung diharapkan bisa menjadi salah satu solusi yang tepat untuk mengatasi hama burung. Penelitian tentang perancangan pesawat udara tanpa awak mirip burung telah banyak dilakukan namun belum khusus dalam pemanfaatannya, seperti [1] perancang dan eksperimen pesawat udara mirip burung dengan kendali jarak jauh. Penelitian ini bertujuan untuk menghasilkan pesawat terbang yang mirip burung yang dapat bertengger layaknya burung sesungguhnya. Penelitian lainnya [2], proses perancangan pesawat tanpa awak mirip burung Elang Alap (Accipter Nisus). Dalam penelitian ini perancangan UAV dilakukan dengan cara meniru anatomi suatu burung dan menyederhanakan bentuk dari wing menjadi bentuk rounded dengan cara membuat skala gambar burung dalam kondisi terbangnya. Penelitian yang serupa dengan tujuan khusus mengendalikan hama burung masih sangat sedikit dipublikasikan, salah satunya [3] adalah perancangan pesawat udara tanpa awak menyerupai burung elang ekor baji (Aquila Audax). Penelitian ini bertujuan untuk menghasilkan rancangan pesawat udara tanpa awak mirip burung untuk mengendalikan hama burung pada area bandara dan arena olah raga.

Penelitian ini fokus pada perancangan awal pesawat udara tanpa awak mirip burung predator untuk tujuan pengendalian hama burung di lahan pertanian. Untuk bisa digunakan sebagai alternatif mengatasi hama burung di lahan pertanian, pesawat udara tanpa awak dirancang mirip burung predator dengan ketinggian dan kecepatan terbang yang rendah menyesuaikan dengan karakter terbang hama burung pipit.

\section{Metodologi Penelitian}

Secara umum tahapan yang dilalui dalam proses perancangan pesawat udara dimulai dari design requirement,conseptual design, detail design sampai dengan manufakturing. Penelitan ini hanya sampai pada tahap conseptual design atau perancangan awal. Sebelum memasuki tahap perancangan awal pesawat tanpa awak mirip burung terlebih dahulu dilakukan penentuan kebutuhan rancangan untuk pesawat, yaitu bentuk pesawat harus mirip burung predator dan karakteristik pesawat menyesuaikan kebiasaan hama burung pipit. Burung predator yang dipilih sebagai acuan perancangan adalah burung elang hitam (Ictinaetus Malaiensis) yang merupakan salah satu predator alami burung - burung kecil termasuk burung pipit. Burung elang hitam ditunjukkan pada gambar 1. Rancangan pesawat akan mengikuti planform sayap dan ekor burung elang hitam termasuk panjang dan beratnya.



Gambar 1. Elang Hitam (Ictinaetus Malaiensis) 
Perancangan awal pesawat udara tanpa awak mirip burung mengikuti proses perancangan pesawat pada umumnya dengan beberapa penyederhanaan. Langkah awal dalam perancangan awal pesawat adalah menentukan misi pesawat sesuai kebutuhan rancangan, selanjutnya menentukan berat total pesawat $\left(W_{T O}\right)$ yang dihitung dengan persamaan 1 .

$$
W_{T O}=W_{E}+W_{P}+W_{S(\text { Battery }+ \text { receiver }+ \text { servos })}
$$

Langkah selanjutnya adalah perhitungan geometri pesawat dengan metode Raymer [4], antara lain geometri sayap dan ekor dengan persamaan 2 sampai 4.

$$
\begin{array}{r}
\frac{W_{T O}}{S_{W}}=\frac{\rho v_{\text {stall }}^{2} C_{L \max }}{2} \\
S_{V T}=\frac{C_{V T} S_{W} b_{W}}{L_{T}} \\
S_{H T}=\frac{C_{H T} S_{W} b_{W}}{L_{T}} \\
L_{H T}=\frac{C_{H T} S_{W} \bar{c}_{W}}{S_{H T}}
\end{array}
$$

Setelah menghasilkan geometri pesawat dari hasil perhitungan dan penyesuaian dengan bentuk planform burung elang hitam, selanjutnya dibuat model tiga dimensi pesawat menggunakan bantuan software CAD.

\section{Hasil dan Pembahasan}

Perancangan pesawat udara tanpa awak mirip burung elang hitam dimulai dengan menentukan design requirement antara lain: bentang sayap $\left(b_{W}\right) 1,48 \mathrm{~m}$, panjang pesawat $0,65 \mathrm{~m}$ dan berat total $\left(W_{T O}\right)=1 \mathrm{~kg}$ semuanya mengikuti ukuran minimum dari konfigurasi elang hitam serta bentuk sayap dan ekor mengikuti planform burung elang hitam. Selain itu parameter design requirement yang lain adalah adalah kecepatan terbang jelajah $\left(v_{c}\right)$ pesawat ditentukan adalah $10 \mathrm{~m} / \mathrm{s}$ dengan ketinggian terbang $7 \mathrm{~m}$ dari permukaan tanah (mengikuti karakter terbang hama burung pipit) dan jarak jelajah $10 \mathrm{~km}$ dengan lama terbang kurang dari 20 menit (meminimalkan penggunaan baterai). Pesawat ini akan menggunakan motor listrik, propeler, electric speed control (ESC), receiver, sistem autopilot (Ardupilot), baterai dan 3 buah servo untuk bidang kendali dengan perkiraan berat total $472 \mathrm{gr}$ yang merupakan komponen berat sistem $\left(W_{S}\right)$ pesawat. Selain itu, pesawat ini juga akan membawa muatan $\left(W_{P}\right)$ berupa sistem audio untuk memaksimalkan fungsi kontrol hama burung berupa speaker seberat 50gr.

Langkah selanjutnya adalah menentukan berat pesawat, dalam hal ini yang belum diketahui adalah berat kosong pesawat menggunakan persamaan 1, diperoleh berat kosong $\left(W_{E}\right)$ pesawat sebesar 478gr. Konfigurasi pesawat tanpa awak mirip burung dipilih bentuk fuselage adalah kotak karena lebih banyak ruang yang tersedia untuk sistem dan muatan dan sistem propulsi tractor. Airfoil yang digunakan untuk sayap adalah bentuk airfoil sayap burung elang [5] sesuai gambar 2 . Nilai koefisien gaya angkat maksimum $\left(C_{L \max }\right)$ sebesar 1,43 pada sudut serang $14^{\circ}$. Sedangkan airfoil yang digunakan untuk ekor adalah NACA0012 sesuai gambar 3.

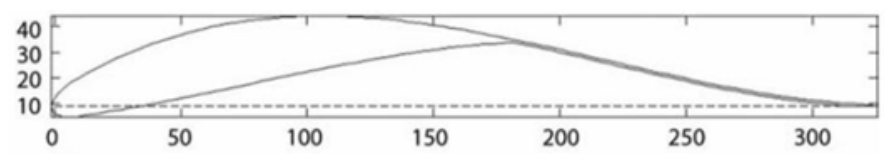

Gambar 2. Airfoil Sayap Burung Elang

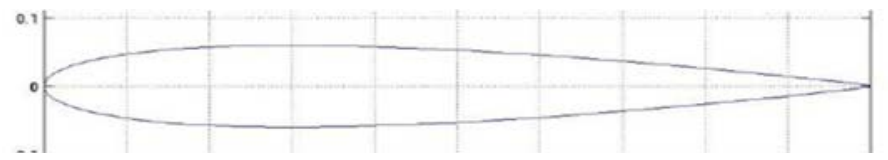

Gambar 3. Airfoil NACA0012 
Selanjutnya, menghitung geometri fuselage berdasarkan metode perhitungan Raymer, untuk pesawat homebuild, rasio antara panjang fuselage $\left(l_{f}\right)$ terhadap diameter fuselage $\left(d_{f}\right)$ adalah 4-8, sehingga diperoleh diameter fuselage $\left(d_{f}\right)$ sebesar $81,25 \mathrm{~mm}$. Bentuk fuselage lingkaran kemudian diubah menjadi bentuk fuselage persegi, sehingga diperoleh lebar fuselage sebesar $71 \mathrm{~mm}$. Geometri sayap pesawat diperoleh dari hasil sketching sayap burung elang hitam pada kondisi terbang jelajah dengan menyederhanakan bagian tepi depan sayap menjadi bentuk lurus sepanjang bentang sayap untuk mempermudah proses manufaktur. Hasil sketching sayap ditunjukkan pada gambar 3 .

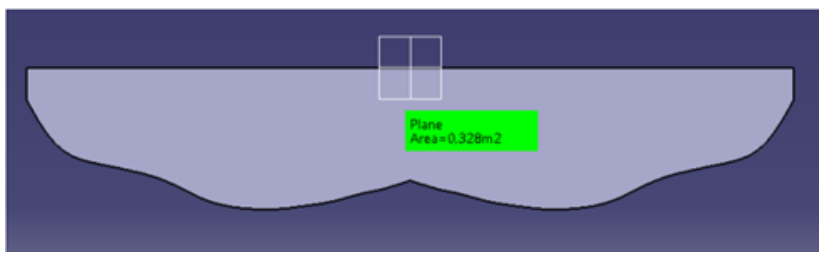

Gambar 3. Hasil Sketching Sayap

Dari hasil sketching sayap diperoleh geometri sayap dengan luas sayap $\left(S_{W}\right) \quad 0,328 \mathrm{~m}^{2}$, aspek rasio sayap $(A R) 6,7$ serta root chord $\left(c_{\text {root }}\right)$ dan tip chord $\left(c_{\text {tip }}\right)$ sayap masing-masing $215 \mathrm{~mm}$ dan $53 \mathrm{~mm}$. Wing loading $\left(\frac{W_{T O}}{S_{W}}\right)$ sayap diperoleh dengan membagi antara berat total pesawat dengan luas sayap, diperoleh sebesar $30 \mathrm{~N} / \mathrm{m}^{2}$. Kecepatan stall $\left(v_{\text {stall }}\right)$ dapat dihitung dengan persamaan 2, diperoleh sebesar $6,16 \mathrm{~m} / \mathrm{s}$. Geometri ekor pesawat diperoleh dengan cara yang sama pada sayap yaitu hasil sketching dari ekor burung elang hitam pada kondisi terbang jelajah. Pesawat udara tanpa awak ini dirancang hanya memiliki ekor horizontal. Hasil sketching ekor ditunjukkan pada gambar 4.

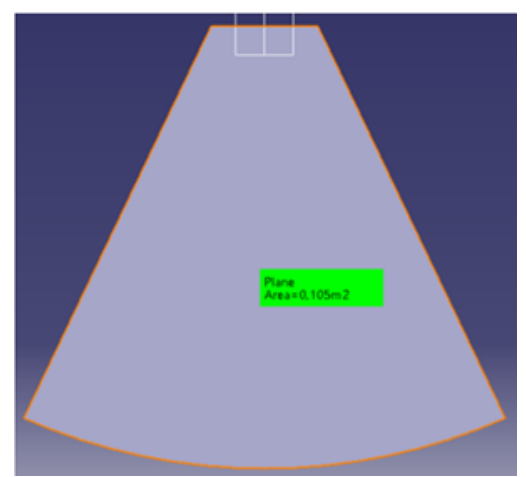

Gambar 4. Hasil Sketching Ekor

Dari hasil sketching ekor dari diperoleh geometri ekor dengan luas ekor $\left(S_{H T}\right) 0,105 \mathrm{~m}^{2}$, root chord dan tip chord ekor masing-masing $395 \mathrm{~mm}$ dan $3 \mathrm{~mm}$. Lengan momen ekor $\left(L_{H T}\right)$ dihitung menggunakan persamaan 4 dengan nilai horizontal tail volume rasio $\left(C_{H T}\right) 0,4$ dan panjang chord sayap rata-rata $\left(\bar{c}_{W}\right) 0,23 \mathrm{~m}$ diperoleh lengan $0,28 \mathrm{~m}$. Selanjutnya perhitungan geometri bidang kendali pesawat. Pesawat ini menggunakan dua bidang kendali yaitu aileron dan elevator. Geometri aileron ditentukan panjang span aileron $\left(b_{A}\right)$ adalah $45 \% b_{W}$ dan chord aileron $\left(c_{A}\right)$ adalah $17 \%\left(\bar{c}_{W}\right)$. Sedangkan untuk geometri bidang kendali elevator ditentukan panjang span elevator $\left(b_{E}\right)$ adalah $100 \% b_{H T}$ dan chord aileron $\left(c_{E}\right)$ adalah $25 \%$ root chord horizontal tail.

Geometri hasil rancangan kemudian dimodelkan dalam bentuk tiga dimensi dengan bantuan software CAD yang akan digunakan sebagai model untuk analisis karakteristik aerodinamika pesawat melalui simulasi komputasi dengan pendekatan dinamika fluida komputasi. Model tiga dimensi pesawat hasil rancangan sesuai gambar 5. 


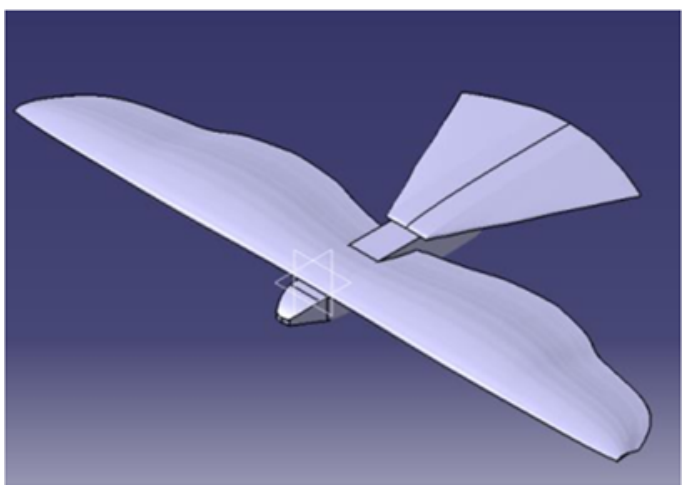

Gambar 5. Model 3D Pesawat Hasil Rancangan

Simulasi komputasi dilakukan dengan parameter yang sama dengan kondisi operasional pesawat rancangan. Ketinggian terbang $7 \mathrm{~m}$ di atas permukaan tanah atau $120 \mathrm{~m}$ di atas permukaan laut (elevasi Yogyakarta $113 \mathrm{~m}$ [6]), kecepatan terbang $\left(v_{c}\right)$ sesuai design requirement $10 \mathrm{~m} / \mathrm{s}$. Hasil simulasi diperoleh karakteristik aerodinamika pesawat sesuai gambar 6.



Gambar 6. Karakteristik Aerodinamika Pesawat Rancangan

Dari hasil simulasi pada gambar 6 , gaya angkat (lift) sesuai kebutuhan rancangan $(9,8 \mathrm{~N}$ atau $1 \mathrm{~kg})$ diperoleh pada sudut serang $(\alpha) 3^{\circ}$, sehingga pesawat ini akan menggunakan sudut pemasangan sayap $\left(\alpha_{i}\right)$ sebesar $3^{\circ}$. Nilai $C_{L \max }$ diperoleh pada sudut serang $(\alpha) 15^{\circ}$ sebesar 1,41. Pesawat akan mengalami kehilangan gaya angkat di antara sudut serang $(\alpha) 15^{\circ}$ dan $18^{\circ}$. Hasil simulasi menunjukkan bahwa nilai gradien momen longitudinal kurang dari nol sehingga memenuhi syarat stabil statis longitudinal.

\section{Kesimpulan}

Pesawat udara tanpa awak mirip burung berhasil dirancang untuk kebutuhan pengendalian hama burung pipit. Hasil rancangan diperoleh geometri pesawat rancangan dengan lebar sayap $\left(b_{W}\right) 1,48 \mathrm{~m}$, panjang pesawat $0,65 \mathrm{~m}$ dan berat total $\left(W_{T O}\right)=1 \mathrm{~kg}$. Bentuk sayap termasuk penampang sayap dan ekor pesawat menyerupai burung mengikuti planform 
burung elang hitam dengan sudut pasang sayap $\left(\alpha_{i}\right)$ sebesar $3^{\circ}$. Pesawat rancangan memiliki kecepatan terbang jelajah $\left(v_{c}\right) 10 \mathrm{~m} / \mathrm{s}$ dengan kecepatan minimum $\left(v_{\text {stall }}\right) 6,16 \mathrm{~m} / \mathrm{s}$. Ketinggian operasional pesawat adalah $120 \mathrm{~m}$ di atas permukaan laut. Hasil simulasi aerodiamika menunjukkan bahwa rancangan pesawat memenuhi syarat kebutuhan gaya angkat untuk pesawat pada sudut serang $(\alpha) 3^{\circ}$ dan memenuhi kriteria kestabilan statis longitudinal yang ditunjukkan oleh gradien koefisien momen negatif.

\section{Daftar Pustaka}

[1] Robertson, D. K., \& Reich, G. W. (2013). Design and perching experiments of bird-like remote controlled planes. In 54th AIAA/ASME/ASCE/AHS/ASC Structures, Structural Dynamics, and Materials Conference (p. 1788).

[2] Yudhono, R., \& Erissonia, A. E. (2018). Design of a Bird-like Fixed-wing Unmanned Aerial Vehicle. In Proceeding of International Conference on Engineering and Natural Sciences-Summer Session 2018.

[3] Muller, B., Clothier, R., Watkins, S., \& Fisher, A. (2015). Design of bio-inspired autonomous aircraft for bird management. In AIAC16: 16th Australian International Aerospace Congress (p. 370). Engineers Australia.

[4] Raymer, D. (2018). Aircraft design: a conceptual approach. American Institute of Aeronautics and Astronautics, Inc..

[5] Carruthers, A. C., Walker, S. M., Thomas, A. L., \& Taylor, G. K. (2010). Aerodynamics of aerofoil sections measured on a free-flying bird. Proceedings of the Institution of Mechanical Engineers, Part G: Journal of Aerospace Engineering, 224(8), 855-864.

[6] https://map-bms.wikipedia.org/wiki/Kota Yogyakarta diakses Maret 2019. 